\title{
Correction to: Pain, Psychological Comorbidities, Disability, and Impaired Quality of Life in Hidradenitis Suppurativa
}

\author{
Zarine S. Patel ${ }^{1,2}$ • Lauren K. Hoffman ${ }^{1,3}$ - Dawn C. Buse ${ }^{4}$ - Amy S. Grinberg ${ }^{2}$ • \\ Ladan Afifi $^{5}$ - Steven R. Cohen ${ }^{1}$ - Michelle A. Lowes ${ }^{1}$ - Elizabeth K. Seng ${ }^{2,6}$
}

Published online: 18 November 2017

(C) Springer Science+Business Media, LLC, part of Springer Nature 2017

Correction to: Curr Pain Headache Rep (2017) 21: 49

https://doi.org/10.1007/s11916-017-0647-3

The original version of this article contains an error in the spelling of the title. The title should read: Pain, Psychological Comorbidities, Disability, and Impaired Quality of Life in Hidradenitis Suppurativa. The correct title is also presented above.

The online version of the original article can be found at https://oi.org/ 10.1007/s11916-017-0647-3

\section{Elizabeth K. Seng}

Elizabeth.Seng@einstein.yu.edu

1 Hidradenitis Suppurativa Treatment Center, Division of Dermatology, Albert Einstein College of Medicine, Montefiore Medical Center, Bronx, NY, USA

2 Ferkauf Graduate School of Psychology, Yeshiva University, 1165 Morris Park Avenue, Rousso Building, Bronx, NY, USA

3 Albert Einstein College of Medicine, Montefiore Medical Center, Bronx, NY, USA

4 Albert Einstein College of Medicine, Montefiore Headache Center, Bronx, NY, USA

5 University of Miami, Miller School of Medicine, Miami, FL, USA

6 Saul R. Korey Department of Neurology, Albert Einstein College of Medicine, Bronx, NY, USA 